Chapter 9

\title{
Fundamental Aspects of Silicon Carbide Oxidation
}

\author{
Heiji Watanabe and Takuji Hosoi \\ Additional information is available at the end of the chapter \\ http://dx.doi.org/10.5772/51514
}

\section{Introduction}

Silicon carbide ( $\mathrm{SiC})$, which exhibits a wider band gap as well as a superior breakdown field and thermal conductivity over conventional $\mathrm{Si}$, has gained considerable attention for future power electronics [1]. Among the various types of power devices, metal-oxide-semiconductor field-effect transistors (MOSFETs), which provide a normally-off characteristic, should become a key component for next-generation green electronics. As stated, with the exception of $\mathrm{Si}, \mathrm{SiC}$ is the only compound semiconductor that yields $\mathrm{SiO}_{2}$ insulators with thermal oxidation. This makes the device fabrication process easier compared with those for other wide band gap semiconductors. It is commonly believed that carbon impurities within the oxides diffuse out in the form of carbon oxides during high temperature oxidation, but a small amount of carbon impurities remains within the oxide and at the $\mathrm{SiO}_{2} / \mathrm{SiC}$ interface. Consequently, the electrical degradation of SiC-MOS devices causing both deteriorated device performance and reliability is the most crucial obstacle to the implementation of $\mathrm{SiC}$ based power electronics.

Unlike mature Si-MOS technology [2-5], a plausible oxidation model of a SiC surface and physical origin explaining electrical degradation of SiC-MOS devices have yet to be established. High-resolution transmission electron microscopy (TEM) observation reported several nm-thick transition layers with an extremely high excess carbon concentration around $20 \%$ beneath the $\mathrm{SiO}_{2} / \mathrm{SiC}$ interface [6-8]. Although the non-stoichiometric bulk region seems to account for the mobility degradation of SiC-MOSFETs [8], a recent report based on an ion scattering technique pointed out a near-perfect stoichometric $\mathrm{SiC}$ region [9].

In addition, there still remain controversial issues of the energy band structure of $\mathrm{SiO}_{2} / \mathrm{SiC}$ interfaces, despite the fact that a small conduction band offset significantly increases the gate leakage current, especially under a high electric field and high operation temperatures [10]. For example, while alternative channels, such as a $4 \mathrm{H}-\mathrm{SiC}(000-1) \mathrm{C}$-face substrate, have 
proven to provide higher electron mobility than conventional devices on Si-face substrates [11], a further reduction in conduction band offset has been pointed out for the C-face channels [12]. However, details on the physical origins have not been clarified yet.

Furthermore, another important problem of $\mathrm{SiC}-\mathrm{MOS}$ devices is poor gate oxide reliability, such as low dielectric breakdown field and threshold voltage instability. It has been reported that the location of dielectric breakdown is not correlated with any dislocations in SiCMOS capacitors with gate oxides formed on $4^{\circ}$-off-angled $4 \mathrm{H}-\mathrm{SiC}(0001)$ substrates by successive oxidation in $\mathrm{N}_{2} \mathrm{O}$ and $\mathrm{NO}$ ambient [13]. Our conductive atomic force microscopy (AFM) study on a thermally grown $\mathrm{SiO}_{2} / 4 \mathrm{H}-\mathrm{SiC}(0001)$ structure has clearly demonstrated that dielectric breakdowns are preferentially induced at the step bunching [14]. It is generally accepted that the gate oxide breakdown is triggered when electrical defects generated in the oxide by a stress field are connected between the electrode and substrate (percolation model) [15]. Thus, we speculated that a local electric field concentration occurred around the step bunching, resulting in the preferential breakdown due to the acceleration of the defect generation. This suggests that oxidation behavior of step-bunched $\mathrm{SiC}$ surface induced by epitaxial growth and high-temperature activation annealing needs to be clarified from the macroscopic point of view, together with the atomic bonding features at $\mathrm{SiO}_{2} / \mathrm{SiC}$ interface mentioned above.

This article provides an overview of our recent studies on the thermal oxidation of $4 \mathrm{H}-\mathrm{SiC}$ substrates and the energy band structure of $\mathrm{SiO}_{2} / 4 \mathrm{H}-\mathrm{SiC}$ fabricated on (0001) Si-face and (000-1) C-face surfaces by means of high-resolution synchrotron x-ray photoelectron spectroscopy (XPS). We investigated the correlation between atomic structure and the electrical properties of corresponding SiC-MOS capacitors and discuss the intrinsic and extrinsic effects of the interface structure and the electrical defects on the band offset modulation. In addition, the surface and interface morphology of a thermally grown $\mathrm{SiO}_{2} / 4 \mathrm{H}-\mathrm{SiC}(0001)$ structure were systematically investigated using AFM and TEM to clarify the relation between step bunching and oxidation kinetics.

\section{Initial oxidation of $4 \mathrm{H}-\mathrm{SiC}(0001)$}

Synchrotron XPS analysis was performed using photon energy of $686.5 \mathrm{eV}$ at BL23SU in the SPring-8 [16]. The starting substrate was as-grown 4 -off-angled $4 \mathrm{H}-\mathrm{SiC}(0001)$ wafer with an n-type epitaxially grown layer. After RCA cleaning and subsequent native oxide removal with a diluted hydrofluoric acid (HF) solution, thermal oxidation was conducted in dry oxygen ambient using a conventional tube furnace at $1100^{\circ} \mathrm{C}$. To remove surface contamination due to air exposure, some of the samples were annealed in situ in an analysis chamber under an ultra-high vacuum condition.

Figure 1(a) represents changes in Si 2p core-level spectra as dry oxidation progresses on the $4 \mathrm{H}-\mathrm{SiC}(0001)$ surface at $1100^{\circ} \mathrm{C}$ [17]. Peak intensity was normalized with the bulk signal. Oxide growth on the $\mathrm{SiC}$ surfaces was confirmed with an increase in the chemical shift component in the Si $2 \mathrm{p}$ core-level spectra at around $104.5 \mathrm{eV}$. Capacitance-voltage $(\mathrm{C}-\mathrm{V})$ 
measurement of the corresponding $\mathrm{Al} / \mathrm{SiO}_{2} / \mathrm{SiC}$ capacitors also revealed that oxidation for 10 and 30 min yielded roughly 3.5 and 5.7-nm-thick oxides, respectively. To investigate atomic bonding feature at $\mathrm{SiO}_{2} / \mathrm{SiC}$ interfaces, $\mathrm{Si} 2 \mathrm{p}$ signals were analyzed by taking into account spin-orbit splitting. Figure 1(b) shows typical deconvoluted $\mathrm{Si} 2 \mathrm{p}_{3 / 2}$ and $2 \mathrm{p}_{1 / 2}$ peak components obtained with the manner adopted in the previous research on $\mathrm{SiO}_{2} / \mathrm{Si}$ interfaces $[3,4]$. Then, the $\mathrm{Si} 2 \mathrm{p}_{3 / 2}$ spectra taken from $\mathrm{SiO}_{2} / \mathrm{SiC}$ were deconvoluted into five components originating from bulk $\mathrm{SiC}$ and $\mathrm{SiO}_{2}$ portions together with intermediate oxide states $\left(\mathrm{Si}^{1+}, \mathrm{Si}^{2+}\right.$, $\mathrm{Si}^{3+}$ ). High-resolution XPS analysis allows us to detect small amount of intermediate states from an atomically abrupt oxide/substrate interface, and, in addition, these intermediate components can be a good indicator of structural imperfection at $\mathrm{SiO}_{2} / \mathrm{SiC}$ interfaces. As shown in Fig. 1(c), we obtained a reasonable curve fitting with these components and confirmed that the total amount of the intermediate states is sufficiently small compared with that of thin thermal oxides. From these results, it is concluded that the physical thickness of the transition layer is as thin as a few atomic layers, which corresponding to areal density of $\mathrm{Si}-\mathrm{O}$ bonds in the range of a few times $10^{15} \mathrm{~cm}^{-2}$. This indicates formation of a near-perfect $\mathrm{SiO}_{2} / \mathrm{SiC}$ interface and coincides well with a recent report based on high-resolution medium energy ion scattering [9].

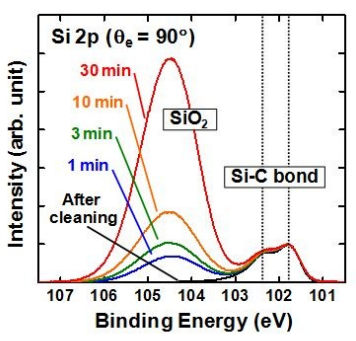

(a)

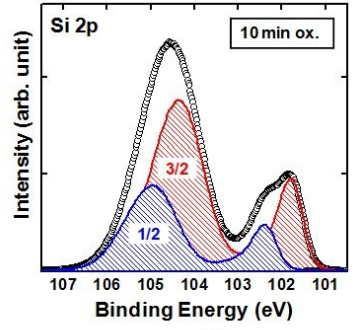

(b)

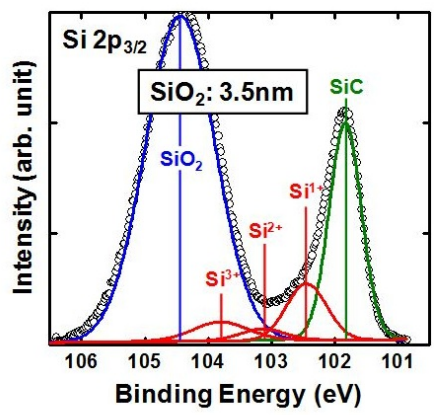

(c)

Figure 1. Synchrotron XPS spectra taken from the cleaned and oxidized $4 \mathrm{H}-\mathrm{SiC}(0001)$ surfaces; (a) change in Si $2 \mathrm{p}$ core-level spectra as dry oxidation progresses, (b) peak deconvolution with $2 p_{3 / 2}$ and $2 p_{1 / 2}$ components, (c) result of curve fitting of $\mathrm{Si} 2 \mathrm{p}_{3 / 2}$ core-level with bulk $\mathrm{SiC}$ and $\mathrm{SiO}_{2}$ signals and intermediate oxide states for the $\mathrm{SiO}_{2} / \mathrm{SiC}$ sample prepared by 10 -min oxidation. 


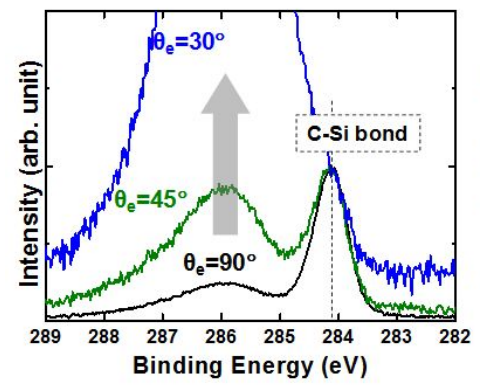

(a)

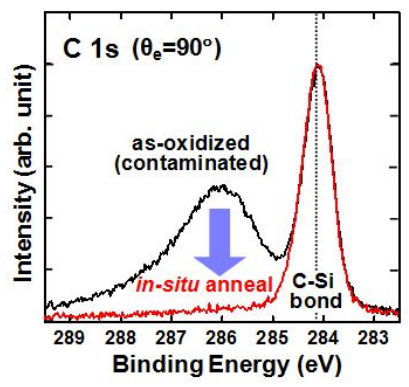

(b)

Figure 2. $\mathrm{C}$ 1s core-level spectra taken from the oxidized $4 \mathrm{H}-\mathrm{SiC}(0001)$ surface using synchrotron radiation; (a) angleresolved XPS analysis, (b) results of in situ vacuum annealing at $500^{\circ} \mathrm{C}$.

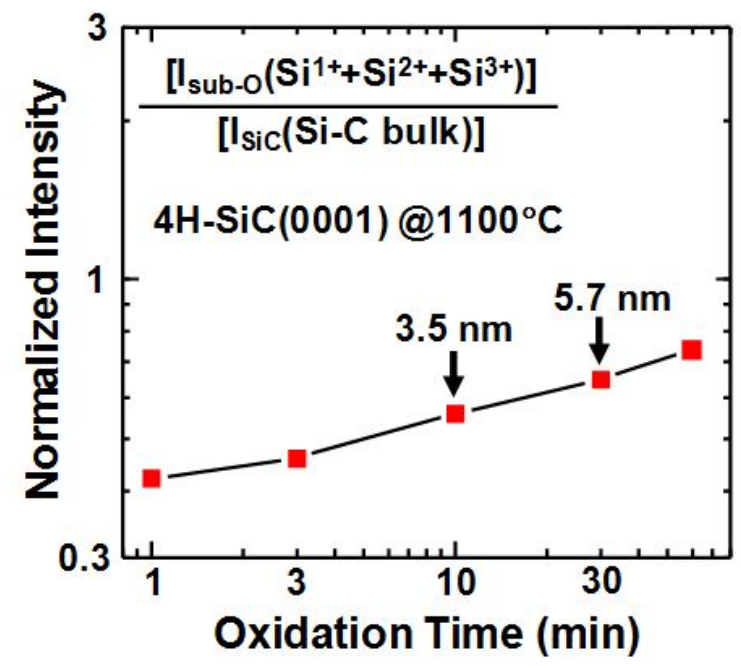

Figure 3. Change in the total amount of intermediate oxide states in $\mathrm{Si} 2 \mathrm{p}_{3 / 2}$ spectra, in which the intensity ratio between the intermediate state and the bulk signal was plotted as a function of oxidation time.

As previously reported, ideal hydrogen passivation of a SiC surface with a diluted HF solution was barely obtained, and the initial sample surface after wet cleaning was partially oxidized and contaminated with adsorbates [18]. This implies that a chemical shift component of C 1s core-level spectra involves unavoidable signals due to surface contamination. Thus, we performed angle-resolved XPS and in situ vacuum annealing prior to XPS analysis in the analysis chamber. Figure 2 represents $\mathrm{C}$ 1s core-level spectra taken from the oxidized $4 \mathrm{H}$ $\mathrm{SiC}(0001)$ surface [17]. As shown in Fig. 2(a), the chemical shift component originating from carbon-oxides $\left(\mathrm{CO}_{\mathrm{x}}\right)$ increased with respect to the bulk signal (C-Si bond) under the surface 
sensitive conditions (at small take-off angle $\left(\theta_{\mathrm{e}}\right)$ ). In addition, it was found that the chemical shift component originating from carbon-oxides was totally removed by vacuum annealing at $500^{\circ} \mathrm{C}$ (see Fig. 2(b)). Since stable chemical bonds existing at the $\mathrm{SiO}_{2} / \mathrm{SiC}$ interface are hard to decompose under a moderate annealing temperature, we attributed the carbon-oxide signal to surface contamination. This clearly demonstrates that atomic bonding at the thermally grown $\mathrm{SiO}_{2} / \mathrm{SiC}(0001)$ interface is dominated by $\mathrm{Si}-\mathrm{O}$ bonds and that carbon impurity with its oxide form located near the interface is below the detection limit of XPS analysis (about sub-1 atomic percent in general).

Figure 3 shows the change in the total amount of intermediate oxide states in $\mathrm{Si} 2 \mathrm{p}_{3 / 2}$ spectra $\left(\mathrm{Si}^{1+}, \mathrm{Si}^{2+}, \mathrm{Si}^{3+}\right)$ [17]. Although a thick transition layer at $\mathrm{SiO}_{2} / \mathrm{SiC}$ interface was ruled out, we observed a slight increase in the intermediate oxide states with an increase of the oxide thickness, unlike in the $\mathrm{SiO}_{2} / \mathrm{Si}$ interface, which exhibits a perfect interface regardless of oxide thickness [4].

\section{Interface structures beneath thick thermal oxides grown on $4 \mathrm{H}$ - SiC(0001) Si-face and (000-1) C-face substrates}

Figures $4(\mathrm{a})$ and $4(\mathrm{~b})$ represent typical deconvoluted Si $2 \mathrm{p}_{3 / 2}$ spectra obtained from the 40 nm-thick $\mathrm{SiO}_{2} / \mathrm{SiC}(0001) \mathrm{Si}$-face and (000-1) C-face substrates, respectively, in which the thick thermal oxides were thinned using a diluted HF solution prior to synchrotron XPS analysis [19]. Similar to the thin thermal oxides (see Fig. 1), the Si $2 p_{3 / 2}$ spectra were fitted well with five components originating from bulk $\mathrm{SiC}$ and $\mathrm{SiO}_{2}$ portions together with intermediate oxide states. It's obvious that, for both cases, the total amount of the intermediate states was sufficiently small compared with that of the remaining oxides (about $3 \mathrm{~nm}$ thick). This implies that the physical thickness of the transition layer on the oxide side is as thin as a few atomic layers even for the thick thermal oxides. These experimental results clearly indicate formation of a near-perfect $\mathrm{SiO}_{2} / \mathrm{SiC}$ interface with conventional dry oxidation regardless of the substrate orientation and oxide thickness.

Furthermore, for the thick thermal oxide on Si-face substrate, the composition of the bulk $\mathrm{SiC}$ region beneath the oxide was estimated from the intensity ratio ([Si $2 \mathrm{p}] /[\mathrm{C} 1 \mathrm{~s}])$. We obtained an identical intensity ratio to that of the initial as-grown $\mathrm{SiC}$ surface [17]. These experimental results mean that, despite previous literature based on TEM observation [6-8], there exists no thick carbon-rich layer of a high atomic percentage at the $\mathrm{SiO}_{2} / \mathrm{SiC}$ interface and that a near-perfect interface dominated by Si-O bonds is formed even for the thick thermal oxidation of the $\mathrm{SiC}(0001)$ surface.

Figure 5 compares the change in the total amount of intermediate oxide states in $\mathrm{Si} 2 \mathrm{p}_{3 / 2}$ spectra obtained from $\mathrm{SiO}_{2} / \mathrm{SiC}$ interfaces. The intensity ratios between the intermediate states and the bulk signals for thin and thick thermal oxides grown on (0001) Si-face and (000-1) C-face substrates were plotted. Despite that the minimal intermediate oxide states again imply abrupt interface, we observed a slight increase in the intermediate states espe- 
cially for thick thermal oxide interface on C-face substrates, which suggesting degradation of interface electrical properties of $\mathrm{SiC}-\mathrm{MOS}$ devices formed on C-face substrates [20].

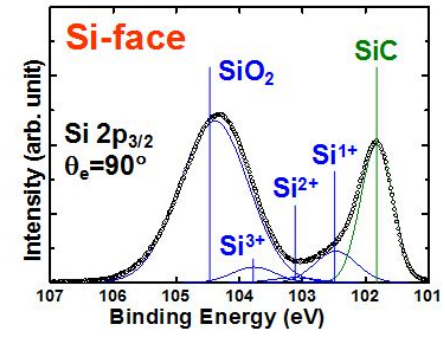

(a)

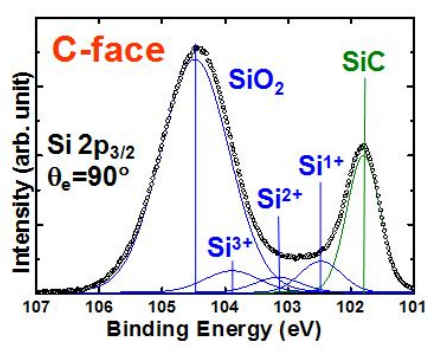

(b)

Figure 4. Si $2 p_{3 / 2}$ core-level spectra obtained from the oxidized (a) $4 \mathrm{H}-\mathrm{SiC}(0001)$ Si-face and (b) (000-1) C-face substrates. Before synchrotron XPS measurement, 40-nm-thick oxide layers were thinned using HF wet etching. The remaining oxide thickness was about $3 \mathrm{~nm}$ for both cases.

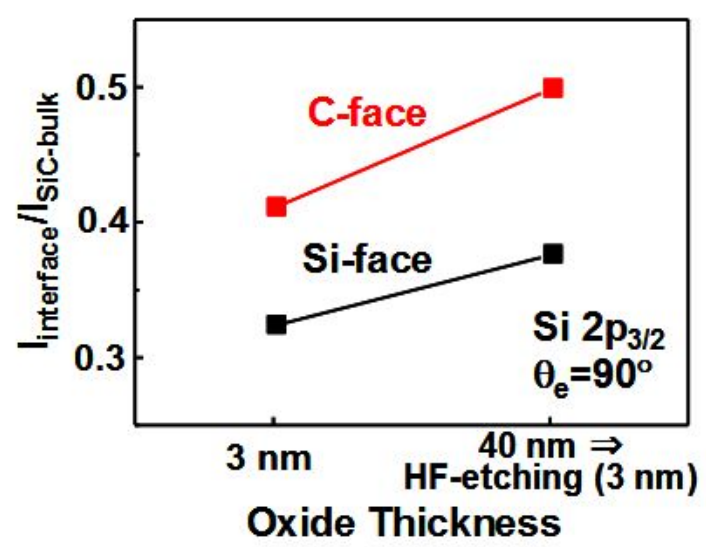

Figure 5. Change in the total amount of intermediate oxide states in $\mathrm{Si} 2 \mathrm{p}_{3 / 2}$ spectra taken from the oxide interfaces grown on $\mathrm{SiC}(0001)$ Si-face and C-face substrates.

\section{Correlation between atomic structure and electrical properties of $\mathrm{SiO}_{2} / \mathrm{SiC}$ interface}

Corresponding SiC-MOS capacitors were fabricated with the top aluminum electrode evaporated through a shadow mask after post oxidation annealing at $900^{\circ} \mathrm{C}$ in argon ambient. Electrical properties, such as the interface state density $\left(\mathrm{D}_{\mathrm{it}}\right)$ and fixed oxide charge den- 
sity $\left(\mathrm{Q}_{\mathrm{ox}}\right)$ of the $\mathrm{SiO}_{2} / \mathrm{SiC}$ interface, were extracted from the high-frequency $\mathrm{C}-\mathrm{V}$ characteristics of SiC capacitors. The $\mathrm{D}_{\mathrm{it}}$ value was extracted with the Terman method, and the $\mathrm{Q}_{\mathrm{ox}}$ was deduced from the flatband voltage $\left(\mathrm{V}_{\mathrm{fb}}\right)$ shift that depends on the oxide thickness [21]. Figure 6 summarizes the changes in $D_{i t}$ and $V_{f b}$ values. Since post-treatment, such as nitrogen and hydrogen incorporation, was not conducted in this experiment, high $D_{i t}$ over $10^{12} \mathrm{~cm}^{-2} \mathrm{eV}^{-1}$ was extracted at an energy level of $\mathrm{E}_{\mathrm{c}}-\mathrm{E}=0.36 \mathrm{eV}$. The high $\mathrm{D}_{\mathrm{it}}$ value indicates degradation of the electrical properties of the $\mathrm{SiO}_{2} / \mathrm{SiC}$ interface, especially for thick thermal oxides. In addition, the positive $\mathrm{V}_{\mathrm{fb}}$ shift in the $\mathrm{C}-\mathrm{V}$ curves implies the existence of a negative fixed charge within the gate oxides. Assuming that the fixed charge is located at the $\mathrm{SiO}_{2} / \mathrm{SiC}$ interface, the $\mathrm{Q}_{\mathrm{ox}}$ of the $\mathrm{SiC}-\mathrm{MOS}$ devices estimated from the thickness- $\mathrm{V}_{\mathrm{fb}}$ slope was $2.3 \times 10^{11} \mathrm{~cm}^{-2}$ for oxides thinner than $20 \mathrm{~nm}$ and $1.2 \times 10^{12} \mathrm{~cm}^{-2}$ for thick oxides, meaning that the fixed charges also accumulated at the interface probably due to the suppressed outdiffusion of carbon impurities as dry oxidation progressed.

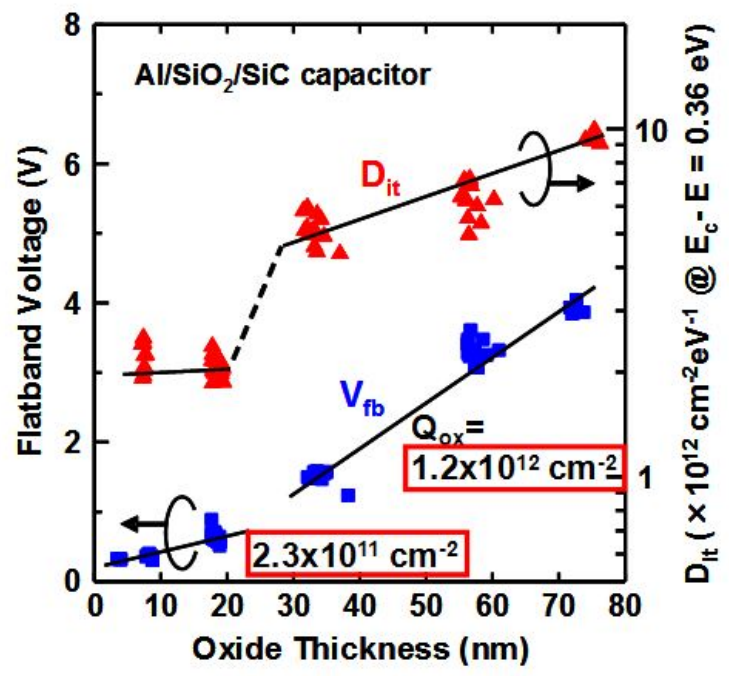

Figure 6. Summary of electrical properties of SiC-MOS capacitors fabricated by dry oxidation. Horizontal axis represents oxide thickness extracted from measured maximum capacitance. The $D_{i t}$ and $Q_{o x}$ were estimated using Terman method and $V_{\mathrm{fb}}$ shift in $\mathrm{C}-\mathrm{V}$ curves, respectively.

The correlation between electrical degradation and the atomic bonding feature of the $\mathrm{SiO}_{2} / \mathrm{SiC}$ interfaces raises the intrinsic problem of $\mathrm{SiC}$ oxidation. This is consistent with the common understanding of SiC-MOS devices, whereas our synchrotron XPS analysis excludes the several-nm-thick transition layer having excess carbon as a physical origin of the electrical degradation. Instead, we think that the electrical defects at the interface, such as $D_{\text {it }}$ and $\mathrm{Q}_{\mathrm{ox}}$, are partly ascribed to the atomic scale roughness and imperfection identified with the intermediate oxide states in the Si $2 \mathrm{p}$ spectra. Moreover, considering the significant mobility reduction in SiC-MOSFETs, we should take into account the various forms of carbon 
interstitials forming local $\mathrm{C}-\mathrm{C}$ dimers located on the $\mathrm{SiC}$ bulk side as a possible origin of the electrical defects [22]. Therefore, it is concluded that, for improving the performance of SiCbased MOS devices, we should focus our attention on the atomic bonding feature and carbon impurities within the channel region rather than the thick transition layer near the $\mathrm{SiO}_{2} / \mathrm{SiC}$ interface.

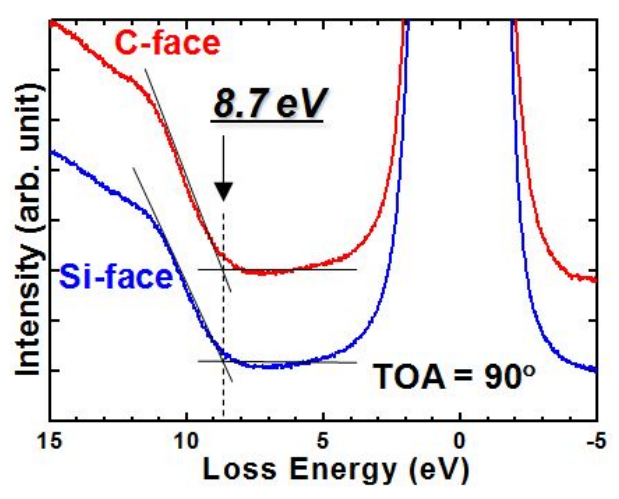

Figure 7. O 1s energy loss spectra for thermal oxides on (0001) Si-face and (000-1) C-face 4H-SiC substrates. The onset of the excitation from the valence to conduction bands (band gap) can be determined from the energy loss. The valence band maximum of $\mathrm{SiC}$ substrates and the oxides was determined by the valence spectra taken $\mathrm{from} \mathrm{SiO}_{2} / \mathrm{SiC}$ structures and a reference SiC surface [24]. Figure 8 represents measured and deconvoluted valence spectra obtained after 3-nm oxidation of the Si-face and C-face substrates, in which the valence band maximum of the thermal oxides was estimated by subtracting the reference $\mathrm{SiC}$ spectra (司) from the measured $\mathrm{SiO}_{2} / \mathrm{SiC}$ spectra (可) both for the $\mathrm{Si}$ - and C-face substrates (see

\section{Energy band structure of $\mathrm{SiO}_{2} / 4 \mathrm{H}-\mathrm{SiC}$ interfaces and its modulation induced by intrinsic and extrinsic interface charge transfer}

The energy band structure and interface quality of $\mathrm{SiO}_{2} / 4 \mathrm{H}-\mathrm{SiC}$ fabricated on (0001) Si-face and (000-1) C-face substrates was also investigated by means of synchrotron XPS. Thermal oxidation was conducted using a conventional furnace at temperatures ranging from 1000 to $1100^{\circ} \mathrm{C}$. Thin and thick oxide layers of about 3 and $40 \mathrm{~nm}$ were prepared by choosing the oxidation temperature and time appropriately for Si-face and C-face substrates. For the thick oxide samples, the oxide layers were thinned to about $3 \mathrm{~nm}$ thick by a diluted HF solution. To determine band structures of $\mathrm{SiO}_{2} / \mathrm{SiC}$, we examined the band gap of the thermal oxides and valence band offset at the interface. The energy band gap of these oxides grown on Si-face and C-face substrates was first estimated from $\mathrm{O}$ 1s energy loss spectra. Because the photoelectrons generated in oxides suffer energy losses originating from plasmon and electron-hole excitations, the energy band gap can be determined by the threshold energy of an energy loss spectrum for an intense O 1s signal [23]. As shown in Fig. 7, O 1s energy loss spectra for thermal oxides on the Si-face and C-face substrates clearly indicate that the energy band gap of the oxides is identical 
regardless of substrate orientation $(8.7 \mathrm{eV})$ [24]. Considering the high oxidation temperatures over $1000^{\circ} \mathrm{C}$ and low concentration of residual carbon impurities within thermally grown oxides on $\mathrm{SiC}$ [17], these results seem to be quite reasonable.

spectra ๑-๑). These results demonstrated that the valence band offset of the $\mathrm{SiO}_{2} / \mathrm{SiC}$ for the C-face substrate was about $0.4 \mathrm{eV}$ larger than that for the Si-face. In addition, we conducted similar synchrotron XPS analysis for thick oxide samples to examine the effects of interface defects on energy band modulation as the oxide thickness increased.

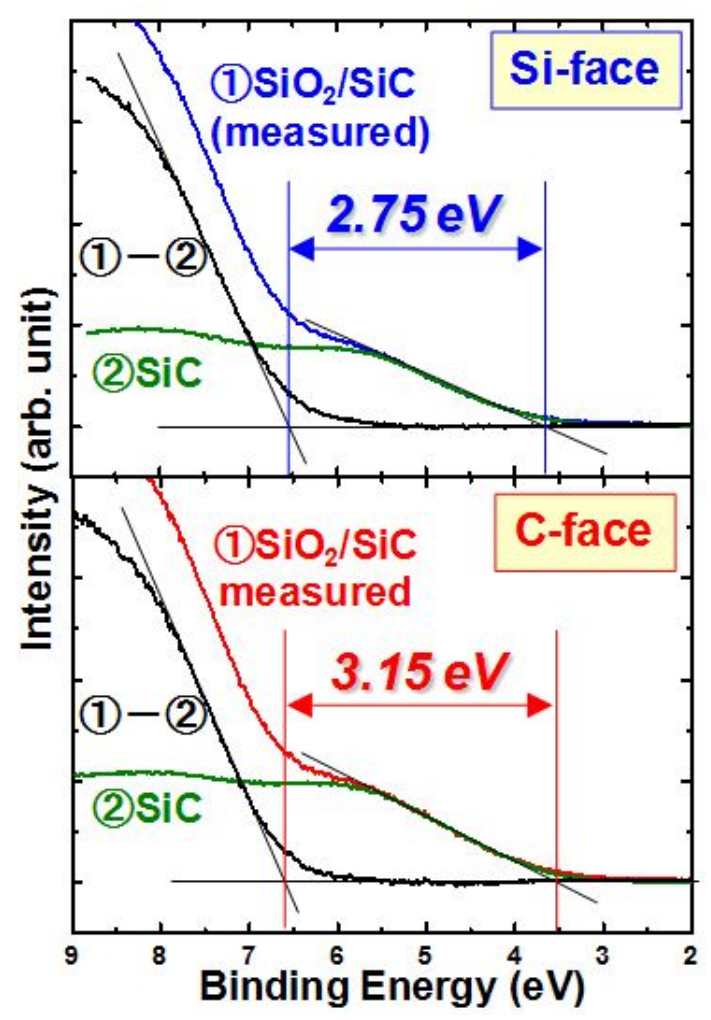

Figure 8. Measured and deconvoluted valence band spectra for $\mathrm{SiO}_{2} / \mathrm{SiC}$ structures formed on (0001) Si-face and (000-1) C-face 4H-SiC substrates.

By taking these measured values and the reported energy band gap of $4 \mathrm{H}-\mathrm{SiC}$ substrate $(3.26 \mathrm{eV})$ into account, we obtained the energy band structures for $\mathrm{SiO}_{2} / \mathrm{SiC}$ structures fabricated under various conditions and summarized them in Fig. 9 [24]. Note that the conduction band offset that determines gate leakage current and resultant gate oxide reliability of SiC-MOS devices crucially depends on the substrate orientation and oxide thickness. Since the thin oxide on the C-face substrates exhibits smaller conduction band offsets than those on the Si-face substrates, we conclude that the degraded reliability of SiC-MOS devices fab- 
ricated on the C-face surface is an intrinsic problem, which is probably due to the difference in the electronegativity between $\mathrm{Si}$ and $\mathrm{C}$ atoms bonded with $\mathrm{O}$ atoms at the interface.

Furthermore, considering the accumulation of negative fixed charges at the $\mathrm{SiO}_{2} / \mathrm{SiC}$ interface, the increase in the conduction band offset for thick oxides both on the Si-face and Cface substrates can be explained by an extrinsic energy band modulation due to the interface defects. This enlarged band offset for the thick MOS devices is preferable from the viewpoint of reducing gate leakage, but electrical defects should negatively impact on the device performance and reliability. Therefore, fundamental tactics, such as applying deposited gate oxides and band engineering by utilizing stacked structures, are indispensable to take advantage of C-face SiC-MOS devices [25-28].

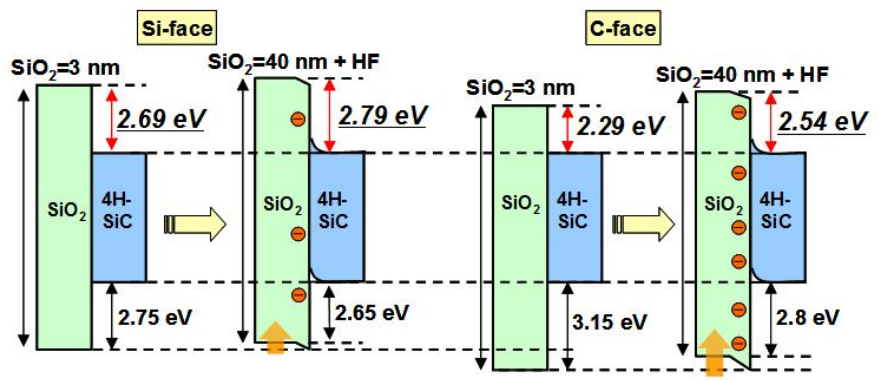

Figure 9. Energy band diagrams of $\mathrm{SiO}_{2} / 4 \mathrm{H}-\mathrm{SiC}(0001)$ structures obtained by synchrotron XPS analysis. The measured values of the valence band offsets for $\mathrm{SiO}_{2} / \mathrm{SiC}$ interfaces formed under various conditions are indicated.

We also evaluated the modulation of energy band alignment of $\mathrm{SiO}_{2} / 4 \mathrm{H}-\mathrm{SiC}(0001)$ structures due to the interface defect passivation [29]. It was found that, although the hydrogen incorporation into the $\mathrm{SiO}_{2} / \mathrm{SiC}$ interface is effective in improving the interface property, both XPS analysis and electrical measurements revealed that interface defect passivation induces a reduction of conduction band offset. This indicates that the larger conduction band offset at the as-oxidized $\mathrm{SiO}_{2} / \mathrm{SiC}$ interface is attributed to the high density of interfacial carbon related defects.

\section{Surface and interface morphology of thermally grown $\mathrm{SiO}_{2}$ dielectrics on $4 \mathrm{H}-\mathrm{SiC}(0001)$}

Finally, surface and interface morphology of thermal oxides grown on 4H-SiC(0001) substrates was investigated using AFM and TEM [30]. Thermal oxidation of $4^{\circ}$-off-angled $4 \mathrm{H}-$ $\mathrm{SiC}(0001)$ Si-face substrate with an n-type epilayer was carried out in dry $\mathrm{O}_{2}$ ambient at $1100^{\circ} \mathrm{C}$ for 12 hours. The root mean square (RMS) roughness of the as-grown surface was estimated to be $0.23-0.26 \mathrm{~nm}$ (see Fig. 10(a)), suggesting that it is an almost step-bunchingfree substrate. However, in some locations, step bunching was observed, and the RMS 
roughness of the area, including step bunching, was about $2.3 \mathrm{~nm}$. For some samples, hightemperature annealing was performed in an inert ambient at $1700^{\circ} \mathrm{C}$ to intentionally emphasize the step bunching prior to the dry oxidation.

As shown in Fig. 10(b), the RMS roughness value of the oxide surface was about $0.36 \mathrm{~nm}$, which is slightly higher than that of the as-grown epilayer surface. In addition, it seems that steps on the oxide surface are more rounded than the initial surface. Figure 11 shows crosssectional TEM images of as-grown and oxidized samples. Single steps are observed at the $\mathrm{SiO}_{2} / 4 \mathrm{H}-\mathrm{SiC}$ interface in contrast to multiple-layer steps for the initial epilayer surface. These findings indicate that the step-terrace structure of an epilayer is enormously transferred to the $\mathrm{SiO}_{2}$ surface, while the interface roughness decreases by smoothening step bunching. Since the oxidation rate for $\mathrm{C}$-face $4 \mathrm{H}-\mathrm{SiC}$ is much higher than that for $\mathrm{Si}$-face, it is considered that the step edges will be rounded by enhanced oxidation and that the resulting oxide near the steps will be thicker due to a volume expansion from $\mathrm{SiC}$ to $\mathrm{SiO}_{2}$.
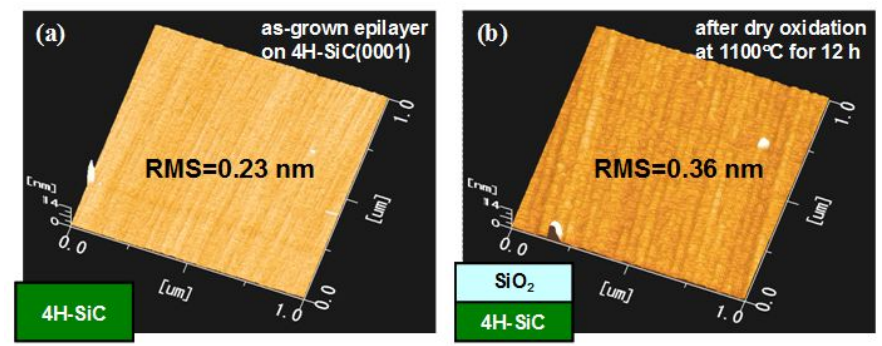

Figure 10. AFM images of (a) as-grown $4 \mathrm{H}-\mathrm{SiC}(0001)$ epilayer surface and (b) $\mathrm{SiO}_{2}$ surface formed on sample shown in (a) by dry $\mathrm{O}_{2}$ oxidation at $1100^{\circ} \mathrm{C}$ for $12 \mathrm{~h}$.
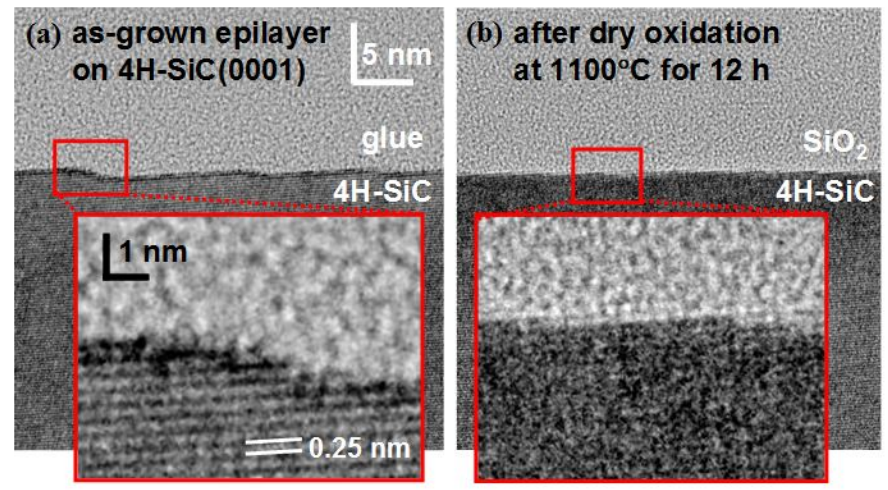

Figure 11. Cross-sectional TEM images of (a) as-grown $4 \mathrm{H}-\mathrm{SiC}(0001)$ epilayer surface and (b) $\mathrm{SiO}_{2} / 4 \mathrm{H}-\mathrm{SiC}$ interface formed on sample shown in (a). The oxide thickness was about $35 \mathrm{~nm}$. 
To verify this hypothesis, a large step bunching was intentionally formed by high temperature annealing. As shown in Fig. 12(a), AFM observation of the 4H-SiC(0001) surface annealed at $1700^{\circ} \mathrm{C}$ showed that the height of the step bunching ranged from 10 to $20 \mathrm{~nm}$, while the RMS roughness within the terrace was $0.19 \mathrm{~nm}$. After oxidation, a similar step-terrace structure to the one observed in Fig. 12(a) is preserved on the oxide surface, except for the bumps around the step bunching (see Fig. 12(b)). However, the RMS roughness in the flat region that was originally a terrace remains unchanged $(<0.19 \mathrm{~nm})$. This result strongly suggests significantly enhanced oxidation at the step face.
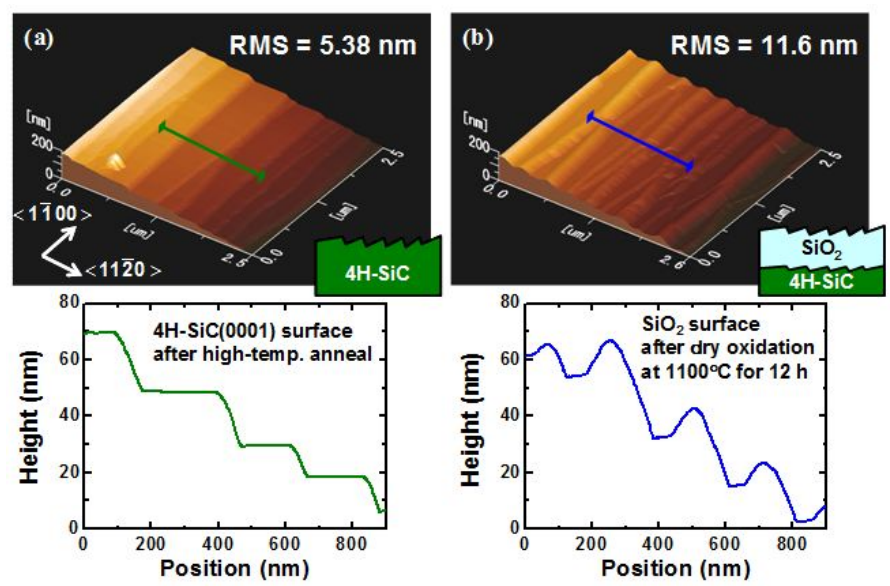

Figure 12. AFM images and cross-sectional profiles of (a) $4 \mathrm{H}-\mathrm{SiC}(0001)$ surface after annealing at $1700^{\circ} \mathrm{C}$ and (b) $\mathrm{SiO}_{2}$ surface formed on the sample shown in (a) by dry oxidation at $1100^{\circ} \mathrm{C}$ for $12 \mathrm{~h}$.

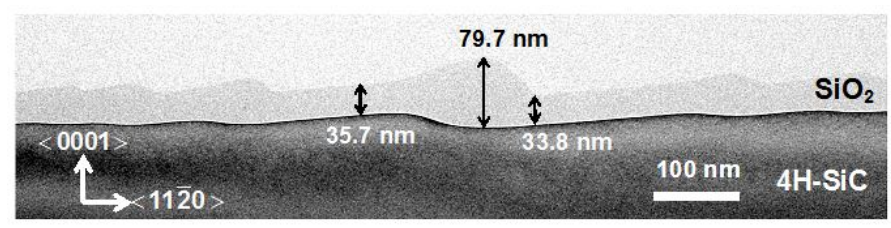

Figure 13. A cross-sectional TEM image of $\mathrm{SiO}_{2} / \mathrm{SiC}$ structure shown in Fig. 12(b).

Furthermore, as shown in Fig. 13, a cross-sectional TEM image of the sample shown in Fig. 12(b) also clearly indicates pronounced oxidation at the step bunching. On the other hand, $\mathrm{SiO}_{2} / 4 \mathrm{H}-\mathrm{SiC}$ interface morphology is clearly more moderated than that of the $\mathrm{SiO}_{2}$ surface, implying that the step bunching at the oxide interface became smooth by oxidation. The maximum $\mathrm{SiO}_{2}$ thickness $(\sim 80 \mathrm{~nm})$ was located facing the step, which is more than double that on the terrace. Since the oxidation reaction is controlled by the amount of oxygen molecules diffused through the $\mathrm{SiO}_{2}$ layer, step edges will become rounded because of the thin- 
ner oxide on the terrace. The large oxide thickness fluctuation surely leads to the local electric field concentration around the step bunching during the electrical stressing, thus resulting in a preferential breakdown. Therefore, we can conclude that the surface morphology of the channel region before gate oxide formation is important for improving reliability of SiC-MOS devices.

\section{Summary}

We have investigated the fundamental aspects of $\mathrm{SiC}$ oxidation and $\mathrm{SiO}_{2} / \mathrm{SiC}$ interfaces. Despite the literature based on TEM observation, we found that a near-perfect interface dominated by $\mathrm{Si}-\mathrm{O}$ bonds is formed by dry oxidation of $4 \mathrm{H}-\mathrm{SiC}(0001)$ substrates. However, atomic scale roughness and imperfection causing electrical degradation of SiC-MOS devices was found to be introduced as oxide thickness increases. We also pointed out the problems regarding oxide reliability originating from the gate leakage. It was found that, although negative fixed charges due to the interface defects enlarge the conduction band offset of SiCMOS devices, small conduction band offset leading to increased gate leakage is an intrinsic feature, especially for the $\mathrm{SiC}(000-1) \mathrm{C}$-face substrates. We have also examined surface and interface morphology of thermally grown oxides to clarify the relation between step bunching and oxide breakdown. Multiple-layer steps as well as step bunching on the wafer surface lead to oxide thickness fluctuation due to the difference in oxidation rate between the terrace and the step face. The bump-like structure of the $\mathrm{SiO}_{2}$ layer near the step bunching and the relatively thinner oxide on the terrace will cause a local electric field concentration, which enhances the generation of electrical defects in the oxide, indicating that an atomically-flat surface needs to be formed before gate oxide formation.

\section{Acknowledgements}

We are grateful to Dr. Takashi Nakamura, Mr. Yuki Nakano, and Mr. Shuhei Mitani for their valuable comments and discussion. Synchrotron XPS experiments were performed at BL23SU in the SPring-8 with the approval of JAEA as Nanotechnology Support Project of the Ministry of Education, Culture, Sports, Science and Technology (MEXT). We also thank Dr. Yuden Teraoka and Dr. Akira Yoshigoe for their assistance for synchrotron XPS measurements.

\section{Author details}

Heiji Watanabe* and Takuji Hosoi

*Address all correspondence to: watanabe@mls.eng.osaka-u.ac.jp 
Department of Material and Life Science, Graduate School of Engineering, Osaka University, Suita, Osaka 565-0871, Japan

\section{References}

[1] Agarwal, A., Ryu, S. H., Palmour, J., Choyke, W. J., Matsunami, H., \& Pensl, G. (2004). Silicon CarbideRecent Major Advances. Springer, Berlin.

[2] Gibson, J. M., \& Lanzerotti, M. Y. (1989). Observation of interfacial atomic steps during silicon oxidation. Nature, 340, 128-131.

[3] Himpsel, F. J., Mc Feely, F. R., Taleb-Ibrahimi, A., \& Yarmoff, J. A. (1988). Microscopic structure of the $\mathrm{SiO}_{2} / \mathrm{Si}$ interface. Phys. Rev. B, 38, 6084-6096.

[4] Ohishi, K., \& Hattori, T. (1994). Periodic changes in $\mathrm{SiO}_{2} / \mathrm{Si}(111)$ interface structures with progress of thermal oxidation. Jpn. J. Appl. Phys., 33, L 675-L678.

[5] Watanabe, H., Kato, K., Uda, T., Fujita, K., Ichikawa, M., Kawamura, T., \& Terakura, K. (1998). Kinetics of initial layer-by-layer oxidation of Si(001) surfaces. Phys. Rev. Lett., 80, 345-348.

[6] Chang, K.C., Nuhfer, N.T., Porter, L.M., \& Wahab, Q. (2000). High-carbon concentrations at the silicon dioxide-silicon carbide interface identified by electron energy loss spectroscopy. Appl. Phys. Lett., 77, 2186-2188.

[7] Zheleva, T., Lelis, A., Duscher, G., Liu, F., Levin, I., \& Das, M. (2008). Transition layers at the $\mathrm{SiO}_{2} / \mathrm{SiC}$ interface. Appl. Phys. Lett., 93, 022108.

[8] Biggerstaff, T. L., Reynolds Jr, C. L., Zheleva, T., Lelis, A., Habersat, D., Haney, S., Ryu, S. H., Agarwal, A., \& Duscher, G. (2009). Relationship between $4 \mathrm{H}-\mathrm{SiC} / \mathrm{SiO}_{2}$ transition layer thickness and mobility. Appl. Phys. Lett., 95, 032108.

[9] Zhu, X., Lee, H. D., Feng, T., Ahyi, A. C., Mastrogiovanni, D., Wan, A., Garfunkel, E., Williams, J. R., Gustafsson, T., \& Feldman, L. C. (2010). Structure and stoichiometry of (0001) 4H-SiC/oxide interface. Appl. Phys. Lett., 97, 071908.

[10] Agarwal, A. K., Seshadri, S., \& Rowland, L. B. (1997). Temperature dependence of Fowler-Nordheim current in $6 \mathrm{H}-$ and $4 \mathrm{H}-\mathrm{SiC}$ MOS capacitors. IEEE Electron Device Lett., 18, 592-594.

[11] Kimoto, T., Kanzaki, Y., Noborio, M., Kawano, H., \& Matsunami, H. (2005). Interface properties of metal-oxide-semiconductor structures on $4 \mathrm{H}-\mathrm{SiC}\{0001\}$ and (1120) formed by $\mathrm{N}_{2} \mathrm{O}$ oxidation. Jpn. J. Appl. Phys., 44, 1213-1218.

[12] Suzuki, T., Senzaki, J., Hatakeyama, T., Fukuda, K., Shinohe, T., \& Arai, K. (2009). Reliability of $4 \mathrm{H}-\mathrm{SiC}(000-1)$ MOS gate oxide using $\mathrm{N}_{2} \mathrm{O}$ nitridation. Mater. Sci. Forum, 557-560. 
[13] Matocha, K, Dunne, G, Soloviev, S, \& Beaupre, R. (2008). Time-dependent dielectric breakdown of $4 \mathrm{H}-\mathrm{SiC}$ MOS capacitors and DMOSFETs. IEEE Trans. Electron Devices, $55,1830-1834$

[14] Kozono, K., Hosoi, T., Kagei, Y., Kirino, T., Mitani, S., Nakano, Y., Nakamura, T., Shimura, T., \& Watanabe, H. (2010). Direct observation of dielectric breakdown spot in thermal oxides on $4 \mathrm{H}-\mathrm{SiC}(0001)$ using conductive atomic force microscopy. Mater. Sci. Forum, 645-648, 821-824.

[15] Degraeve, R., Groeseneken, G., Bellens, R., Ogier, J. L., Depas, M., Roussel, P. J., \& Maes, H. E. (1998). New insights in the relation between electron trap generation and the statistical properties of oxide breakdown. IEEE Trans. Electron Devices, 45, 904-911.

[16] Teraoka, Y., \& Yoshigoe, A. (2001). Commissioning of surface chemistry end-station in BL23SU of SPring-8. Appl. Surf. Sci., 169-170, 738 -170.

[17] Watanabe, H., Hosoi, T., Kirini, T., Kagei, Y., Uenishi, Y., Chanthaphan, A., Yoshigoe, A., Teraoka, Y., \& Shimura, T. (2011). Synchrotron x-ray photoelectron spectroscopy study on thermally grown $\mathrm{SiO}_{2} / 4 \mathrm{H}-\mathrm{SiC}(0001)$ interface and its correlation with electrical properties. Appl. Phys. Lett., 99, 021907.

[18] Watanabe, H., Ohmi, H., Kakiuchi, H., Hosoi, T., Shimura, T., \& Yasutake, K. (2011). Surface cleaning and etching of $4 \mathrm{H}-\mathrm{SiC}(0001)$ using high-density atmospheric pressure hydrogen plasma. J. Nanosci. Nanotechnol., 11, 2802-2808.

[19] Watanabe, H., Hosoi, T., Kirino, T., Uenishi, Y., Chanthaphan, A., Yoshigoe, A., Teraoka, Y., Mitani, S., Nakano, Y., Nakamura, T., \& Shimura, T. (2012). Synchrotron radiation photoelectron spectroscopy study of thermally grown oxides on $4 \mathrm{H}$ SiC(0001) Si-face and (000-1) C-face substrates. Mater. Sci. Forum, 697-702.

[20] Dhar, S., Feldman, L. C., Wang, S., Isaacs-Smith, T., \& Williams, J. R. (2005). Interface trap passivation for $\mathrm{SiO}_{2} /(000-1)$ C-terminated 4H-SiC. J. Appl. Phys., 98, 014902.

[21] Sze, S.M. (1981). Physics of Semiconductor Devices. Wiley, New York.

[22] Devynck, F., \& Pasquarello, A. (2007). Semiconductor defects at the 4H-SiC(0001)/ $\mathrm{SiO}_{2}$ interface. Physica, B 401-402, 556-559.

[23] Miyazaki, S., Nishimura, H., Fukuda, M., Ley, L., \& Ristein, R. (1997). Structure and electronic states of ultrathin $\mathrm{SiO}_{2}$ thermally grown on $\mathrm{Si}(100)$ and $\mathrm{Si}(111)$ surfaces. Appl. Surf. Sci., 113-114, 585-589.

[24] Watanabe, H., Kirino, T., Kagei, Y., Harries, J., Yoshigoe, A., Teraoka, Y., Hosoi, T., \& Shimura, T. (2011). Energy band structure of $\mathrm{SiO}_{2} / 4 \mathrm{H}-\mathrm{SiC}$ interfaces and its modulation induced by intrinsic and extrinsic interface charge transfer. Mater. Sci. Forum, 679-680, $386-389$.

[25] Noborio, M, Suda, J, Beljakowa, S, Krieger, M, \& Kimoto, T. (2009). 4H-SiC MISFETs with nitrogen-containing insulators. Phys. Status Solidi A, 206, 2374-2390. 
[26] Hosoi, T., Harada, M., Kagei, Y., Watanabe, Y., Shimura, T., Mitani, S., Nakano, Y., Nakamura, T., \& Watanabe, H. (2009). AlON $/ \mathrm{SiO}_{2}$ stacked gate dielectrics for $4 \mathrm{H}-\mathrm{SiC}$ MIS devices. Mater. Sci. Forum, 615-617, 541 -544.

[27] Hosoi, T., Kagei, Y., Kirino, T., Watanabe, Y., Kozono, K., Mitani, S., Nakano, Y., Nakamura, T., \& Watanabe, H. (2010). Improved characteristics of 4H-SiC MISFET with AlON/nitrided $\mathrm{SiO}_{2}$ stacked gate dielectrics . Mater. Sci. Forum, 645-648, 991 -994.

[28] Hosoi, T., Kagei, Y., Kirino, , Mitani, S., Nakano, Y., Nakamura, T., Shimura, T., \& Watanabe, H. (2011). Reduction of charge trapping sites in $\mathrm{Al}_{2} \mathrm{O}_{3} / \mathrm{SiO}_{2}$ stacked gate dielectrics by incorporating nitrogen for highly reliable $4 \mathrm{H}-\mathrm{SiC}$ MIS devices. Mater. Sci. Forum, 679-680, 496-499.

[29] Hosoi, T., Kirino, T., Chanthaphan, A., Uenishi, Y., Ikeguchi, D., Yoshigoe, A., Teraoka, Y., Mitani, S., Nakano, Y., Nakamura, T., Shimura, T., \& Watanabe, H. (2012). Impact of interface defect passivation on conduction band offset at $\mathrm{SiO}_{2} / 4 \mathrm{H}-\mathrm{SiC}$ interface. Meter. Sci. Forum, 712-720, 721-724.

[30] Hosoi, T., Kozono, K., Uenishi, Y., Mitani, S., Nakano, Y., Nakamura, T., Shimura, T., \& Watanabe, H. (2011). Investigation of surface and interface morphology of thermally grown $\mathrm{SiO}_{2}$ dielectrics on $4 \mathrm{H}-\mathrm{SiC}(0001)$ substrates. Mater. Sci. Forum, 679-680, 342-345. 